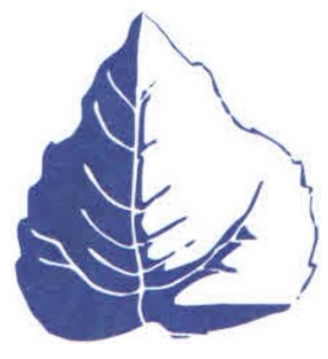

УДК 332.741

\section{МЕЛИОРАЦИЯ, РЕКУЛЬТИВАЦИЯ И ОХРАНА ЗЕМЕЛЬ MELIORATION, RECULTIVIATION AND LAND PROTECTION}

https://doi.org/10.23947/2413-1474-2019-3-4-73-81

Анализ социально-экономических показателей развития страны

и Ростовской области для целей рационального использования территории

Овчинникова Н. Г., Жидкова Е. И., Тимофеева В. А.

Донской государственный технический университет, г. Ростов-на-Дону, Российская Федерация

\title{
Analysis of socio-economic indicators in the country and the Rostov region for the purpose of rational territory use
}

Ovchinnikova N. G., Zhidkova E. I., Timofeeva V. A.

Don state technical University, Rostov-on-don, Russian Federation

Вся деятельность человека тесно связана с землей, которая выступает как основа и средство производства. Поэтому участки земли все чаще становятся объектами товарно-хозяйственных отношений. В связи с этим необходимо проводить анализ социально-экономических показателей развития страны, региона путем определения стоимости объекта или отдельных прав в отношении оцениваемого объекта недвижимости, включая определение стоимости права собственности или иных прав, например, права аренды, права пользования и т. д. с целью дальнейшего рационального использования территории.

Целью рационального использования территории является получение наиболее достоверной информации о цене объектов недвижимости на текущий момент. Одним из объектов недвижимости является земельный участок. Согласно статье 6 Земельного кодекса Российской Федерации, земельный участок представляет собой часть земной поверхности и имеет характеристики (граница, площадь, местоположение, целевое назначение), позволяющие определить ее в качестве индивидуально определенной вещи. Имея анализ социально-экономической показателей, можно, отталкиваясь от них, строить дальнейшие планы на недвижимое имущество, а также проводить сделки с ним. Цена, как денежное выражение стоимости, является суще-
All human activity is closely connected with the land, which acts as the basis and means of production. Therefore, land plots are increasingly becoming objects of commodity-economic relations. For this purpose it is necessary to analyze the socio-economic indicators with the aim of further rational use of the territory by determining the value of the object or individual rights with respect to the assessed property, including the determination of the value of the right of ownership or other rights such as lease rights, use rights, etc. concerning the rational use of the territory.

The purpose of rational use of the territory is to obtain the most reliable information about the price of real estate at the current time. One of the properties is a plot of land. In Accordance with article 6 of the Land code of the Russian Federation, a land plot is a part of the earth's surface and has characteristics (border, area, location, purpose) that allow defining it as an individually defined thing.

Having an analysis of socio-economic indicators, you can start from them, make further plans for real estate, as well as conduct transactions with it. Price, as a monetary expression of value, is an essential component of any transaction, acting as a mechanism that regulates the market turnover of land property for the rational use of the territory. 
ственной составляющей любой сделки, выполняя функции механизма, который регулирует рыночный оборот земельной собственности для рационального использования территории.

Ключевые слова: объект недвижимости, территория, оценка, земельный участок, рациональное использование, экономическое развитие страны, социальные показатели.

Образец для цитирования: Овчинникова, Н. Г. Анализ социально-экономических показателей развития страны и Ростовской области для целей рационального использования территории / Н. Г. Овчинникова, Е. И. Жидкова В. А. Тимофеева // Экономика и экология территориальных образований. - 2019. - Т.3, № 4. C. 73-81.https://doi.org/10.23947/2413-1474-2019-34-73-81
Keywords: real estate object, territory, assessment, land plot, rational use, economic development of the country, social indicators.

For citation: N. G. Ovchinnikova, E. I Zhidkova., V. A. Timofeeva. Analysis of socio-economic indicators in the country and the Rostov region for the purpose of rational territory use. Economy and ecology of territorial formations, 2019, vol. 3, no 4, pp.73-81. https://doi.org/10.23947/2413-1474-2019-34-73-81

Введение. Давно известно, что все объекты недвижимости в системе рационального использования территории имеют важнейшее значение для любой страны: для населения, частного бизнеса, а также для экономики [1-2]. Речь идет не только о строениях, предназначенных для жилья (квартиры, ИЖС, дома), земельных участках, но и о капитальных ресурсах, используемых для общественных целей, для производства и реализации средств производства и предметов потребления (земельные участки, складские здания) [3].

Цены на недвижимость и объёмы строительства прямо зависят от общественных потребностей, а также уровня доходов бизнеса и населения. Однако рынок объектов недвижимости инерционен, так как психология его участников обычно отстаёт от политических и экономических изменений. В результате этого может наблюдаться необоснованный рост либо заторможенность рынка, дефицит некоторых видов недвижимости либо перенасыщение рынка. И как следствие - происходит колебание рыночных цен.

Также можно отметить, что поведение рынка недвижимости и его состояние как в целом по стране, так и по регионам прямо зависят от положения и роли страны в мировой экономике, от уровня и перспектив ее экономического развития, а также от уровня и перспективы региональной экономики [4]. Цель данной статьи - проанализировать политическую и экономическую обстановку в стране и Ростовской области, чтобы определить характер ее воздействия на развитие исследуемой территории.

Сбор и анализ данных, характеризующих экономические, социальные и другие факторы, которые влияют на рациональное использование территории в масштабах страны, города, района и микрорайона, на которых расположен тот или иной объект недвижимости. По данным Федеральной службы государственной статистики Российской Федерации (Росстат), экономический рост за 2018 год ускорился с 1,6 до 2,3\% по сравнению с 2017 годом. Темпы роста валового внутреннего продукта превзошли оценки Минэкономразвития России на 1,7\% в декабре.

Что касается отраслевого резерва, то здесь ключевыми драйверами экономического роста стали промышленность (рост - 0,6 процентных пункта) и строительство, вклад в экономический рост которого составил 0,3 процентных пункта. Также положительное влияние на динамику роста валового внутреннего продукта оказали торговля и транспортная отрасль, их вклад в экономический рост - 0,3 и 0,2 процентных пункта соответственно. Но на фоне положительных примеров экономического роста 
имеются и отрицательные. Это касается, в частности, сельского хозяйства, где снизились урожаи ряда ключевых культур, в первую очередь зерновых, и замедлился рост продукции животноводства. Около 0,8 процентного пункта роста валового внутреннего продукта было обеспечено сектором услуг. Ускорение роста по сравнению с предыдущим годом наблюдалось в финансовой и страховой деятельности, а также в деятельности гостиниц и ресторанов. Замедлился экономический рост только в сфере операций с недвижимостью.

Темп роста оборота розничной торговли в 2018 году по сравнению с 2017 годом увеличился с 1,3 до 2,6\% вследствие расширения спроса на товары длительного пользования. Так, рост продаж легковых автомобилей в 2018 году составил 12,8\%, тогда как в 2017 году он составлял всего лишь 11,9\%. Иные же составляющие потребительского спроса показали замедление темпов роста. К примеру, покупки в зарубежных интернет-магазинах с января по сентябрь 2018 года выросли на 6,5\% в долларовом эквиваленте после роста на $83,9 \%$ в 2017 году. В целом расходы домашних хозяйств на конечное потребление в 2018 году выросли на 2,2\% по сравнению с годом ранее.

Несмотря на то, что в 2018 году в реальном выражении наблюдались высокие темпы роста заработных плат ( $+6,8 \%)$, реальные располагаемые доходы населения с учетом единовременной выплаты пенсионерам на $0,2 \%$ снизились. В это же время динамика показателя для различных доходных групп была неоднородной.

Рост промышленного производства в 2018 году ускорился до 2,9\% по сравнению с 2,1\% в 2017 году. Рост выпуска продукции промышленности в 2018 году был достаточно равномерным. Вследствие этого темпы роста выпуска продукции в течение года оставались в пределах $2-4 \%$, в то время как в 2017 году диапазон колебаний составлял практически 9 процентных пунктов. Положительную динамику по итогам года показали все крупные отрасли промышленности.

В течение 2018 года наблюдалось перераспределение источников экономического роста от внутреннего спроса к внешнему. Основной вклад в рост валового внутреннего продукта в 2018 году внес потребительский спрос, увеличение которого составило 2,2\% по сравнению с 3,2\% в 2017 году. Оборот розничной торговли в 2018 году вырос на 2,6\% за счет увеличения спроса на продукцию длительного пользования. Второй год подряд автомобильный рынок показывает двузначный рост. В 2018 году он вырос на 12,8 \%, тогда как в 2017 году он составлял 11,9\%. Кроме этого, в 2018 году по сравнению с 2017 годом ускорился рост оборота общественного питания - с 3,2 до 3,6\%, что стало результатом прошедшего в России чемпионата мира по футболу.

Ситуация на рынке труда в 2018 году характеризовалась активным ростом заработной платы. Он наблюдался как в социальных, так и во внебюджетных секторах (рис. 1). По предварительным данным Росстата, в целом за 2018 год рост реальной заработной платы составил 6,8\%, в 2017 году он составлял всего лишь 2,9\%. Существенное увеличение темпов роста заработных плат в 2018 году было связано, в первую очередь, с достижением соотношений, установленных указами президента Российской Федерации в части повышения оплаты труда отдельных категорий работников бюджетной сферы. По оценке Минэкономразвития России, темпы роста заработных плат в социальном секторе экономики с января по ноябрь составили $16,8 \%$. 
В 2018 г. рост реальной заработной платы ускорился..

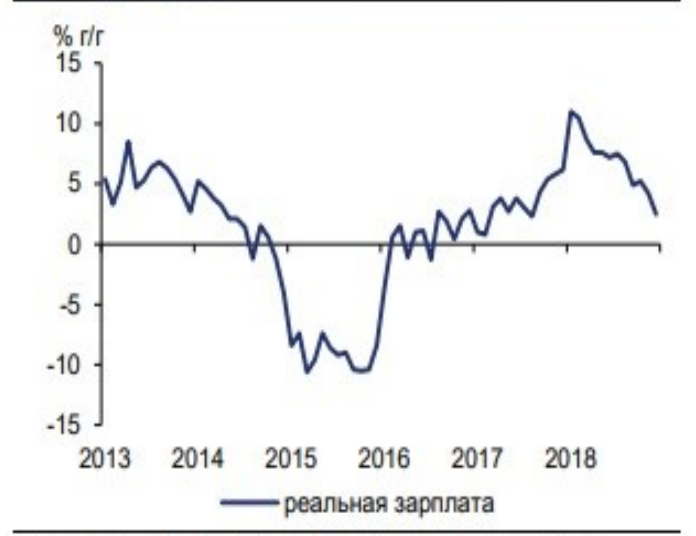

Источник Poсcmam, расчеты Минзкономразвития России. Дека6ры 2018 а. - оценка Poсcmama.

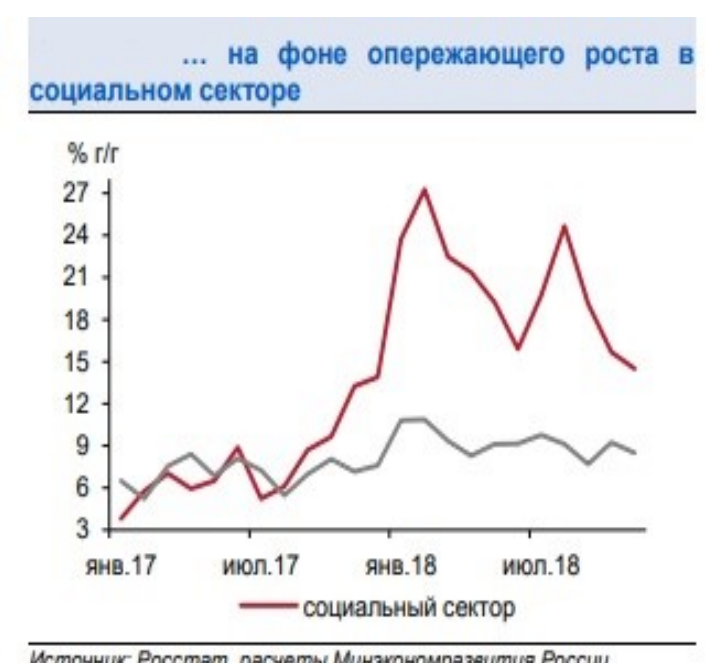

Источник. Pосстат, расчеты Минзкономразвития Pоссии.

Рис. 1. Рост заработной платы в 2018 году

В 2018 году уровень безработицы опустился до исторического минимума в 4,8\% (рис. 2). В целом совокупная численность рабочей силы за 2018 год изменилась незначительно, по сравнению с 2017 годом снизилась на 95,3 тысячи человек, то есть на 0,1\%. При этом отмечалось дальнейшее перераспределение рабочей силы между занятым и безработным населением. Численность занятого населения увеличилась на 215,7 тысячи человек $(+0,3 \%)$, за счет снижения общей численности безработных — на 311,0 тысяч человек $(-7,8 \%)$.
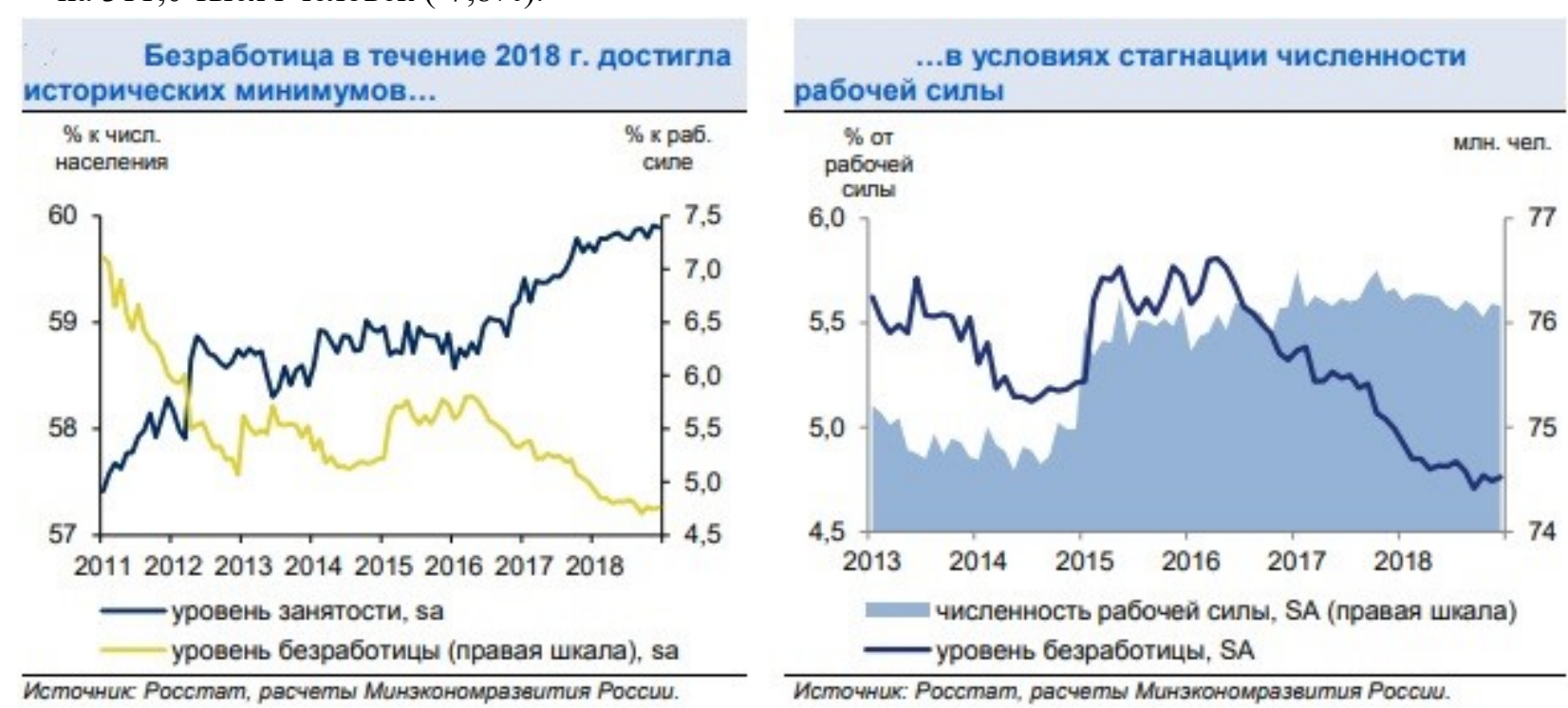

Рис. 2. Уровень безработицы в 2018 году

Инфляция в январе 2019 года составила 1,0\%, что оказалось ниже официального прогноза Минэкономразвития России. По сравнению с соответствующим периодом предыдущего года инфляция в январе 2019 года ускорилась до 5,0\% после 4,3\% в декабре 2018 года. С учетом данных за первые несколько дней февраля, показывающих замедление среднесуточного темпа роста цен, можно сделать вывод о том, что эффект от повышения налога на добавленную стоимость оказался меньше предварительных оценок. Значимый вклад, а именно $+0,24$ процентных пункта, в январе в инфляцию внесла индексация регулируемых цен и тарифов. При этом надо отметить, что стоимость коммунальных услуг возросла на 2,6\%, в том числе в результате повышения налога на добавленную стоимость и за счет введения изменений в порядок платы за услуги по вывозу твердых бытовых отходов. 
В 2018 году профицит счета текущих операций достиг наиболее высокого значения за все время наблюдений. По итогам года положительное сальдо текущего счета увеличилось до 114,9 млрд долл. США после 33,3 млрд долл. США, которое наблюдалось в 2017 году. Максимальный профицит данного счета был обеспечен в связи с увеличением нефтегазового экспорта $(+32,5 \%)$ на фоне положительной ситуации на мировых рынках энергоносителей.

Нефтегазовый экспорт, по итогам прошедшего года, также показал уверенный рост - на 13,6\% по сравнению с ростом в 2017 году. Значительный рост наблюдался, в первую очередь, на товары сырьевой группы, а именно на уголь - $+25,9 \%$ в стоимостном и $+10,0 \%$ в натуральном выражении. В рост несырьевого неэнергетического экспорта наибольший вклад внесла продукция металлургии, как черной, так и цветной. В частности, в 2018 году стоимостной объем экспорта алюминия вырос на $2,7 \%$. Положительная динамика в стоимостном выражении наблюдалась и по другим товарным группам, таким как химические товары, продовольствие, а также продукция машиностроения и деревообработки.

Что касается общей политической и социально-экономической обстановки в Ростовской области и в городе Ростове-на-Дону, то можно назвать следующие характеристики [5].

Ростов-на-Дону - административный центр Ростовской области и Южного федерального округа, население составляет 1133307 человек. Располагается город в юго-восточной части ВосточноЕвропейской равнины, на берегах реки Дон, в 46 километрах от места ее впадения в Азовское море. Площадь города составляет 348 км². $^{2}$

В состав Ростовской области входят 463 муниципальных образования, среди которых выделяют 12 городских округов и 43 муниципальных района. Муниципальные районы, в свою очередь, подразделяются на городские поселения, их насчитывается 18 , и сельские поселения - 390.Вся территория области располагается в юго-восточной части Восточно-Европейской равнины. По территории области протекает река Дон, которая является одной из крупнейших рек Европы, ее длина составляет 1870 км.

Ростов-на-Дону является крупным административным, культурным, научно-образовательным, промышленным центром и важнейшим транспортным узлом юга России. Неофициально город Ростов именуют воротами Кавказа и южной столицей России, а также донской и комбайновой столицей. Распространено понятие «Ростов-папа».

Позиционирование в качестве столицы юга России и локализация в городе промышленных предприятий и структур южнороссийского масштаба (управление СКЖД, штаб ЮВО и другие) обусловливают дополнительную концентрацию в Ростове-на-Дону рабочих мест, обеспечивают повышенный уровень инвестиционной привлекательности и хозяйственной активности.

Фактором, благоприятствующим социально-экономическому развитию города, является и его позиционирование в качестве ядра Ростовской агломерации с демографическим потенциалом до 2 млн человек, формирующего крупнейший на юге России локальный потребительский рынок, который концентрирует значительную часть научно-образовательного, индустриального и финансово-инвестиционного потенциала региона, способствует развитию сельскохозяйственного производства [6-9].

В 2018 году в Ростовской области значения многих индикаторов социально-экономического развития оказались выше, чем в среднем по России. Вместе с тем на фоне высоких показателей 2017 года наблюдается некоторое замедление темпов роста отдельных отраслей экономики.

Оборот организаций с января по апрель 2018 года составил 1 132,0 млрд рублей, или 103,6\% к уровню аналогичного периода 2017 года. Наибольший рост оборота обеспечен предприятиями, которые занимаются добычей полезных ископаемых, операциями с недвижимостью, транспортировкой и хранением, а также строительством [10-11]. Снижение темпов оборота зафиксировано на отдельных предприятиях и в организациях обрабатывающих производств, сельского, лесного хозяйства, рыболовства и рыбоводства, охоты, деятельности гостиниц и предприятий общественного питания, а также профессиональной, технической и научной деятельности [12]. 
Индекс промышленного производства области с января по апрель 2018 года составил 94\% по сравнению с тем же периодом 2017 года, в Российской Федерации он составил 102,8\%. Максимальное влияние на динамику показателей оказали предприятия обрабатывающей промышленности.

По таким видам деятельности, как добыча полезных ископаемых, обеспечение электроэнергией, паром и газом, кондиционирование воздуха, водоотведение, водоснабжение, организация сбора и утилизация твердых бытовых отходов, деятельность, направленная на ликвидацию загрязнений, зафиксировано резкое увеличение объемов производства [13].

Добыча полезных ископаемых в исследуемом периоде по сравнению с январем-апрелем 2017 года выросла на 16,2\%, в Российской же Федерации рост составил всего 4,6\%. Наибольший вклад в отраслевой рост внесли предприятия по добыче угля, добыча и обогащение антрацита увеличились на $31,3 \%$ и 25,3\% соответственно. При этом наблюдалось и снижение показателей. Так, добыча газа уменьшилась на 4,3\%, а добыча прочих полезных ископаемых - на 11,4\%. Объем отгруженной продукции собственного производства, выполненных работ и услуг собственными силами на предприятиях добывающего сектора составил 11,4 млрд рублей. Наибольшие объемы добычи полезных ископаемых, которые составили 8,6 млрд рублей, или 75,6\% от общего объема добычи, приходятся на предприятия, специализирующиеся на добыче угля.

Предприятиями обрабатывающих производств с января по апрель 2018 года отгружено продукции собственного производства, а также выполнено работ и услуг собственными силами на 258,6 млрд рублей, что составляет $75,7 \%$ совокупного объема отгруженной промышленной продукции. В результате выпуск продукции на предприятиях по 12 видам деятельности увеличен, в девяти из них темпы роста составили $113,4-215,6 \%$.

В машиностроительном секторе, где сформировано около $23,2 \%$ общего объема отгруженной продукции обрабатывающих производств, по сравнению с январем-апрелем 2017 года выросло производство автотранспортных средств, прицепов и полуприцепов на $13,3 \%$, производство машин и оборудования, не включенных в другие группировки, возросло на 15,6\%, производство электрического оборудования также увеличилось - на $15,5 \%$. Тем временем в Российской Федерации в рассматриваемый период производство автотранспортных средств, прицепов и полуприцепов выросло на 3,8\%, а производство электрического оборудования, наоборот, снизилось на 4\%, производство машин и оборудования, не включенных в другие группировки, также уменьшилось - на 1,9\%.

Больше, чем в январе-апреле прошлого года, изготовлено генераторов переменного тока, многофазных электродвигателей переменного тока, трансформаторов электрических, машин для уборки зерновых, бобовых, масличных и крупяных культур, зерноуборочных комбайнов, а также прочих принадлежностей и комплектующих для автотранспортных средств. Наряду с этим спад на 8,2\% наблюдался в производстве компьютеров, электронных и оптических изделий, в Российской Федерации, наоборот, зафиксирован рост на $0,5 \%$. Производство прочих транспортных средств и оборудования, так же, как и в Российской Федерации, претерпело понижение - на 48,6\% и 21,1\% соответственно.

Заключение. Проанализировав общую политическую и макроэкономическую обстановку в стране и Ростовской области, можно сделать вывод, что основные показатели развития страны и региона оказывают положительное воздействие на развитие исследуемой территории [14-15]. Также можно сделать вывод, что объекты недвижимости занимают особое место в любой экономической системе, так как с ними прямо или косвенно связаны социальные, экономические интересы людей, а также хозяйственная деятельность. В данном случае недвижимость выступает как естественный пространственный базис, на котором осуществляется вся жизнедеятельность людей, она составляет основу национального богатства страны.

\section{Библиографический список}

1. Овчинникова, Н. Г. Разработка и принятие проектных решений по организации рационального использования земельных ресурсов / Н. Г. Овчинникова // Известия Ростовского государственного строительного университета. — 2011. — № 15. - С. 225-230. 
2. Овчинникова, Н. Г. Организационно-правовые формы хозяйствования в современных условиях / Н. Г. Овчинникова, А. С. Чешев // Инженерный вестник Дона. — 2011. - № 1 (15). - С.279288.

3. Чешев, А. С. Экологические аспекты формирования землепользования в новых условиях хозяйствования / А. С. Чешев, Н. Г. Овчинникова / Terra economicus. - 2008. - T. 6, № 3-3 - - C.68-70.

4. Белокрыс, А. М. Основы оценки стоимости недвижимости / А. М. Белокрыс, В. С. Болдырев, Т. Л. Олейник. - Москва : Международная академия оценки и консалтинга, 2004. — 450 c.

5. Овчинникова, Н. Г. Методика улучшения использования земельного базиса в сфере аграрного природопользования / Н. Г. Овчинникова // Инженерный вестник Дона. - 2013. — № 2 (25). C. 135.

6. Овчинникова, Н. Г. Учетно-регистрационный процесс в системе управления земельными ресурсами / Н. Г. Овчинникова, Е. С. Шумкова // Экономика и экология территориальных образований. - 2016. - № 2. - С. 125-129.

7. Овчинникова, Н. Г. Формирование механизма обоснования устойчивого землепользования / Н. Г. Овчинникова // Terra economicus. - 2009. - Т. 7, № 2-2. - C. 41-44.

8. Овчинникова, Н. Г. Социально-экономические аспекты становления сельскохозяйственного землепользования / Н. Г. Овчинникова // Terra economicus. — 2009. — T. 7, № 3-3. - C. 90-93.

9. Овчинникова, Н. Г. Социо-эколого-экономическое моделирование процессов управления земельными ресурсами в сфере сельскохозяйственного производства / Н. Г. Овчинникова // Terra economicus. - 2011. - T. 9, № 3-2. - C. 89-91.

10. Овчинникова, Н. Г. Анализ использования земельных ресурсов на территории Ростовской области / Н. Г. Овчинникова // Проблемы рационального природопользования и пути их решения : сборник материалов Всероссийской научно-практической конференции, посвященной 45-летию ФГБОУ ВО «ДГТУ». — Махачкала, 2018. — С. 245-249.

11. Овчинникова, Н. Г. Роль оценки земельных угодий в оптимизации развития города / Н. Г. Овчинникова, С. С. Струсь, Д. С. Смоляков // Научное обозрение. - 2012. — № 6. - С. 566-568.

12. Овчинникова, Н. Г. Рассмотрение особенностей муниципальных образований РФ как целостной территориальной системы / Н. Г. Овчинникова, В. В. Шмакова // Экономика и экология территориальных образований. - 2017. - № 3. - С. 31-36.

13. Русских, А. В. Роль территорий, опережающих социально-экономическое развитие, в системе их эффективного использования / А. В. Русских, Н. Г. Овчинникова // Организационно-экономические проблемы регионального развития в современных условиях : материалы научно-практической конференции молодых ученых, аспирантов, студентов. - Симферополь, 2018. - С. 279-281.

14. Калитвенцева, А. А. Земельные ресурсы как базис эффективного развития территории / А. А. Калитвенцева, А. В. Петренко, Н. Г. Овчинникова // Организационно-экономические проблемы регионального развития в современных условиях : материалы научно-практической конференции молодых ученых, аспирантов, студентов. - Симферополь, 2018. - С.140-143.

15. Зерщиков, А. М. Стратегия территориального развития муниципальных образований / А. М. Зерщиков, Н. Г. Овчинникова // Организационно-экономические проблемы регионального развития в современных условиях : материалы научно-практической конференции молодых ученых, аспирантов, студентов. - Симферополь, 2018. - С. 122-124.

\section{References}

1. Ovchinnikova, S.G. The development and adoption of design decisions on the organization of the rational use of land resources. Proceedings of the Rostov State University of Civil Engineering. 2011, № 15. 225-230 pp. (in Russian).

2. Ovchinnikova, N.G. Organizational and legal forms of business in modern conditions. Engineering Don Vestnik, 2011, № 1 (15), 279-288 pp. (in Russian). 
3. Cheshev, A.S. Environmental aspects of land use in the formation of new economic conditions. Terra economicus, 2008, V.6, № 3-3, 68-70 pp. (in Russian).

4. Belokris, A.M., V.S.Boldirev, T.L. Oleinik. A framework for assessing property values, Moscow, Intern-l academy of consulting, 2004, 450 p. (in Russian).

5. Ovchinnikova, V.G. Methods of improving the use of the land base in the sphere of agrarian nature management. Engineering Don Vestnik, 2013, № 2 (25), 135 p. (in Russian).

6. Ovchinnikova, N.G., Shumakova, E.S. Accounting and registration process in the land administration system. Economy and ecology of territorial formations, 2016, № 2, 125-129 pp. (in Russian).

7. Ovchinnikova, N.G. Formation mechanism study of sustainable land management. Terra economicus, 2009, V.7, № 2-2, 41-44 pp. (in Russian).

8. Ovchinnikova, N.G. Socio-economic aspects of the formation of agricultural land use. Terra economicus, 2009, V.7, № 3-3, 90-93 pp. (in Russian).

9. Ovchinnikova, N.G. Socio-ecological-economic modeling land management processes in agricultural production. Terra economicus, 2011, V.9, № 3-2, 89-91 pp. (in Russian).

10. Ovchinnikova, N.G. The analysis of land use in the territory of the Rostov region. Environmental management problems and their solutions: collection of materials of All-Russian scientific-practical conference dedicated to the 45th anniversary DSTU, Makhachkala, 2018, 245-249 pp. (in Russian).

11. Ovchinnikova, N.G. The role of assessment of land in the optimization of the city's development. Scientific review, 2012, № 6, 566-568 pp. (in Russian).

12. Ovchinnikova, N.G., V.V. Shmakov. Consideration of the characteristics of the Russian Federation municipalities as an integrated territorial system. Economy and ecology of territorial formations, 2017, № 3, 31-33 pp. (in Russian).

13. Ruskikh, A.V. The role of territories, leading socio-economic development in the system of their effective use. Organizational and economic problems of regional development in modern conditions: materials of scientific-practical conference of young scientists, post-graduate students, Simferopol', 2018, 279-281 pp. (in Russian).

14. Kalitventseva, A.A., Petrenko, A.V., Ovchinnikova N.G. Organizational and economic problems of regional development in modern conditions: materials of scientific-practical conference of young scientists, post-graduate students, Simferopol', 2018, 140-143 pp. (in Russian).

15. Zerschikov, A.M., Ovchinnikova, N.G. The strategy of spatial development of municipalities: materials of scientific-practical conference of young scientists, post-graduate students, Simferopol', 2018, 122 124 pp. (in Russian).

Поступила в редакцию 14.10.2019

Сдана в редакцию 14.10 .2019

Запланирована в номер 05.11.2019
Received 14.10.2019

Submitted 14.10.2019

Scheduled in the issue 05.11.2019 


\section{Об авторах:}

\section{Овчинникова Наталья Геннадьевна,}

доцент кафедры «Экономика природопользования и кадастра» Донского государственного технического университета (РФ, 344000, г. Ростовна-Дону, пл. Гагарина, 1), кандидат экономических наук, доцент

donong160875@yandex.ru

\section{Жидкова Екатерина Ивановна,}

студентка кафедры «Экономика природопользования и кадастра» Донского государственного технического университета (РФ, 344000, г. Ростов-на-Дону, пл. Гагарина, 1),

ekaterinaivanovna98@mail.ru

\section{Тимофеева Виктория Анатольевна,}

студентка кафедры «Экономика природопользования и кадастра» Донского государственного технического университета (РФ, 344000, г. Ростов-на-Дону, пл. Гагарина, 1),

Vichka-20-18@mail.ru
Authors:

\section{Ovchinnikova, Natalya G.,} associate professor, the department of «Economics of Nature Management and Cadaster», Don State Technical University, (1, Gagarin Square, Rostovon-Don, 344000, RF), aassociate pprofessor, $\mathrm{PhD}$ in Economics donong160875@yandex.ru

Zhidkova Ekaterina Ivanovna, a student of the Department "Economics of nature management and cadaster" Don State Technical University (1, Gagarin Square, Rostov-on-Don, 344000, RF), ekaterinaivanovna98@mail.ru

Timofeeva Victoria Anatolyevna, a student of the Department "Economics of nature management and cadaster" Don State Technical University (1, Gagarin Square, Rostov-on-Don, 344000, RF).

Vichka-20-18@mail.ru 